\title{
A EXAUSTÃO DE SÍSIFO \\ ARTICULAÇÃO ENTRE TOYOTISMO, NEOLIBERALISMO E TEORIA DO CAPITAL HUMANO
}

\author{
Rafael Alves da Silva
}

\begin{abstract}
RESUMO
Da articulação entre as técnicas atuais de gestão da produção, o ideário que sustenta o conceito de capital humano e as políticas neoliberais, resulta uma apropriação e reificação dos saberes dos trabalhadores e, conseqüentemente, a precarização dos mesmos. Tais práticas são camufladas num discurso que prega a competição como evolução e as novas práticas como ganhos qualitativos de sentido no trabalho, facilitando a cooptação destes trabalhadores. Palavras chave: toyotismo, qualidade total, neoliberalismo, capital humano
\end{abstract}

\section{THE SISYPHUS' EXHAUSTION \\ ARTICULATION BETWEEN TOYOTISM, NEOLIBERALISM AND HUMAN CAPITAL THEORY}

\begin{abstract}
From the articulation between actual production administration technics, the idea that suports the human capital concept and the neoliberals politics, results an appropriation and reification of the workers' knowledge, and consequent precarization of them. This custom are covered by a discourse that pleat the competition as an evolution and the new customs as qualitative gains to the work's meaning, facilitating the collaboration of this workers. Keywords: toyotism, total quality, neoliberalism, human capital
\end{abstract}

\section{Introdução}

Este texto pretende comentar tendências gerais presentes na empresa contemporânea no tocante às suas técnicas de gestão e o ideário predominante na sociedade relacionado a esse contexto. As mutações que ocorreram nas últimas décadas, sobretudo a partir dos anos 70, no plano econômico, social, político e ideológico, de forma interligada, consistem na manifestação 
virulenta do projeto hegemônico do capital e em sua resposta às pressões sociais intensificadas em fins dos anos 60 .

O discurso neoliberal aponta para a constante escassez de recursos financeiros, age na retração de mecanismos de seguridade social vigentes até então e na desregulamentação da legislação trabalhista e dos mercados, além de privilegiar a individuação e a competição.

As atuais técnicas de gestão - o toyotismo ou ohnismo, as ferramentas de gestão, os mais diversos sistemas de padronização, o conceito da qualidade total - atuam se apropriando dos saberes dos trabalhadores, padronizando suas atividades, de forma a possibilitar a troca de efetivos - até mesmo realizando mudanças geográficas na produção -, a precarização da situação do trabalhador através de terceirizações e simplificação da tarefa e, ao mesmo tempo, a intensificação da produção e do trabalho para os que permanecem na ativa. Esses efeitos ainda são camuflados pelas falsas crenças de ganho de sentido no trabalho, à medida que a empresa dá ênfase à "colaboração", à participação dos trabalhadores com suas idéias, à igualdade e redução das distâncias hierárquicas, ao horário flexível, etc. Se não fosse o suficiente, a facilidade em fragmentar a produção e precarizar funções na medida em que os sistemas avançam em sua padronização e informatização do trabalho, resulta em uma maior dificuldade de resistência por parte dos trabalhadores, seja devido à redução do poder de barganha pelo enorme exército de reserva (qualificado) e pela perda de importância em seus saberes que já foram convertidos em capital de conhecimento, seja pela dificuldade de cooperação e organização entre estagiários, temporários, terceiros, efetivos, estáveis, etc.

Além dessas características no plano econômico e político, no ideológico prevalece a crença do indivíduo como único responsável pela sua empregabilidade e colocação no mercado. O capitalismo atual declaradamente difere do período do fordismo-keynesianismo, e apresenta-se como um sistema onde há lugar para os "melhores" e os indivíduos devem "lutar" pela sua qualificação "investindo" em si, ou seja, na sua carreira. Atender as ferramentas de gestão atuais é sempre aprender e aumentar seu "capital humano", além do que, resistir a elas seria expressão de falta de flexibilidade, cooperação, criatividade, adaptabilidade, etc.

Em resumo, da articulação desses fatores resulta o indivíduo com maior necessidade de se vender, único responsável pelos resultados dos quais depende, em última instância, sua sobrevivência, em constante competição com os demais, "sempre alerta", pois, além do trabalho ultrapassar o espaço da fábrica, há a exigência de constante qualificação e mergulhado nessa lógica, seja devido à contingência e necessidade de manter o emprego, seja acreditando no enriquecimento de seu capital humano. $O$ trabalhador trabalha 
muito na forma de organização atual e, onde esta organização já alcançou certo grau de eficiência, trabalha para sua própria exclusão.

\section{A empresa moderna - quando Sísifo desejou apenas levantar a pedra}

Imagine como é ter um trabalho que precisa ser feito, você é da manutenção, tem de consertar os equipamentos, mas tem de aprender como organizar a oficina de um jeito padronizado para o mundo, depois colocar em prática essa organização, montar um case para apresentar à gerência como isso foi feito, além disso, preencher todos os formulários que comprovam que suas atividades estão sendo realizadas, pois o auditor de ISO 9000 (qualidade) avaliará esses registros quando auditar se a empresa faz manutenção preventiva, cuidar de preencher todos os formulários de disposição de resíduos para a auditoria de ISO 14000 (meio ambiente), participar do grupo de Braimstorm que está avaliando o problema de prazo de entrega e das reuniões do grupo de satisfação do cliente, trabalhar sobre os contratos do programa cliente - fornecedor (você precisa de peças do departamento de compras, a produção precisa do seu serviço - o que sempre aconteceu agora deve ser feito sob contratos com prazos e detalhamentos) e, lembremos, que os equipamentos continuam precisando de manutenção.

Cada uma dessas ferramentas terá um consultor por trás, auditores, um gerente responsável ou trainee que recebeu um projeto. Note como a sua carga de trabalho aumentou. Perceba daqui um tempo que, em casa, você fica pensando na idéia que tem de dar para o Braimstorm do prazo de entrega e o grupo de satisfação do cliente. Os equipamentos têm de ser consertados ou a produção pára, portanto logo você está levando para casa os relatório que tem de preencher, pois não basta que eles sejam consertados, é preciso registrar como, quando e porque. É um registro que ficará para a empresa, para ela medir e entender o departamento.

Teremos um problema se você começar a questionar qual a diferença que tudo isso está fazendo, pois sai um programa e entra outro. Os consultores mudam a todo o momento, os diretores mudam, são expatriados, promovidos. Você continua na manutenção. Sabe que aprendeu muita coisa, mas... Percebe que o que sabe mesmo é consertar equipamentos, todas as ferramentas de gestão que teve de aprender para se adequar, sabe apenas um pedaço, sabe atendê-las, não sairá por ai prestando consultoria. Na verdade, você não sabe muita coisa, pois logo essa ferramenta muda, a moda é outra e você tem de aprender tudo de novo. Até pode ser que terceirizem a manutenção, assim que algum gerente estudar todos os relatórios que você preenche e entender o funcionamento do setor e de qual empresa, profissional e contrato ele precisa. 
Mas, se você ficar desempregado, não será por muito tempo, pois a empresa lhe ensinou uma série de ferramentas da qualidade, do meio ambiente, que aumentaram a sua empregabilidade a um nível... Um nível que... Até você achar outro emprego está bem baixo, pois as ferramentas já mudaram e muitos garotos estão saindo do SENAI sabendo melhor de manutenção que você, pois novos equipamentos e ferramentas (de verdade) surgiram enquanto você se ocupava decidindo qual bicho você era no programa que cada um da empresa era um bicho e atuaria com suas qualidades para melhor atendê-la - e você era o leão, pois valentemente avançava nos motores queimados, nas roldanas soltas. Como eles se livraram do leão? Leões só são eficientes enquanto jovens, a experiência é para os elefantes.

Aí você percebe que todos os dados que levantou e registrou sobre suas atividades, não serviram para você ser promovido como argumentaram, que você tinha de ensinar o que sabia ou nunca poderia ir para um lugar melhor, mas sim para que você fosse substituível. Levado por esse raciocínio, questiona as ferramentas de gestão que tinha de atender - $5 \mathrm{~S}$, Braimstorm, Ishikawa, etc. -, percebe como elas aumentavam o trabalho e representavam uma atividade ainda mais sem sentido, pois mudavam a cada novo mandamento dos consultores que a cada hora tinham uma fórmula. Lembra que sempre ouvia que as ferramentas de gestão aumentavam a participação de vocês da manutenção e da produção, pois interferiam na administração da empresa, mas agora vê que nas decisões você não era envolvido, apenas dava idéias nas reuniões e apresentava sugestões. Você não foi consultado para ser dispensado da manutenção.

Será que ao invés de lhe trazer conhecimentos novos, todos os programas da qualidade da empresa visavam aprender seus saberes? Será que, ao invés de lhe proporcionar maiores possibilidades, os benefícios por metas o colocavam numa armadilha de aumento da dedicação, já que a meta sempre mudava e crescia? Será que até mesmo o dia dos familiares visitarem a empresa era pensado para que você limpasse bem seu setor? E você achou que era uma camaradagem da empresa seu filho poder entrar lá. Agora percebe que ele nunca mais deixou de cobrar que você usasse óculos de segurança no trabalho e, em casa, parecia que você ouvia o técnico da segurança. Falando sobre a sua casa, já fazia tempo que seu trabalho não acabava quando batia o ponto. Ou você tinha relatórios para preencher, ou tinha de estudar, ou estava preocupado com a participação em alguma daquelas reuniões. Até nos fins de semana você acabava indo para a empresa, pois a confraternização com os amigos era no clube dela. Aliás, muitas vezes você não queria ir, mas ficava chato, inclusive leu em algum lugar que ir ao happy hour aumenta as chances de promoção. Quem iria fazer greve contra uma empresa tão "camarada"? Quem iria reclamar por algo 
com tanta gente precisando de emprego e, dentro da própria empresa, vários querendo o seu lugar ou a vaga que você queria? Não podia confiar neles.

Mas é melhor parar de pensar nisso tudo, pois na velocidade que as coisas mudam, logo o que você sabe não serve para nada. Independente das ferramentas da qualidade que você aprendeu não consertarem as máquinas, são elas que serão seu diferencial para o próximo emprego e são o que muda mais rápido. $\bigcirc$ que você tem é o que sabe, isso eles também diziam, que a cada treinamento você aumentava seu capital humano, mas é uma realidade que esse seu capital só vale dentro de uma empresa, então pare de questionar essas coisas e encontre logo outro emprego, pois seu capital está depreciando.

\section{Capital humano - "Invista em você" (jargão publicitário e corporativo)}

Ao longo do tempo, as idéias de sustentação do capitalismo foram se modificando. Com a complexidade alcançada pelas empresas após a segunda guerra, a figura do "empreendedor" do início do século XX havia se modificado. O "espírito do capitalismo" como descrito por Weber já não habitava mais o indivíduo, havia sido substituído por um espírito de grupo. Num quadro de grandes empresas, com vários acionistas, o indivíduo disciplinado que poupa e trabalha duramente deu lugar para o empregado dependente.

Muitos autores se debruçaram sobre as transformações do pós-guerra, como Whyte, W. Mills, Riesman e Schumpeter. Grosso modo, assistia-se a uma sociedade em que os índices de produção eram bastante elevados, as novas gerações saídas das faculdades tinham como projeto entrar e permanecer até o fim da vida numa grande companhia. O vigor de outros tempos do capitalismo estava se perdendo.

A teoria do capital humano surge no início dos anos de 1960, tendo como expoente Theodore Schultz, professor de economia da Escola de Chicago. Inicialmente, o objetivo de tal estudo era o de resolver problemas econômicos, mas não se pode negar a influência que teve na sociedade e na forma de orientar a conduta de empresas e a vida das pessoas. ${ }^{2}$

Embora anteriormente já se encontrassem outros indícios do conceito de capital humano e Marx já apontasse que o trabalhador teria de transformar tudo em algo à venda - "Tudo que tens se deve tornar venal, isto seja,

\footnotetext{
2 LOPEZ-RUIZ,O. O ethos dos executivos das transnacionais e o espirito do capitalismo. Tese de doutorado em Ciências Sociais, IFCH - Unicamp, Campinas, 2004 - histórico dessas teorias e evolução dos conceitos nas páginas de 34 a 46.
} 
proveitoso" ${ }^{3}$-, foi com a Escola de Economia de Chicago que uma teoria econômica passou a pensar o humano explicitamente como capital e um conjunto de valores pôde ser sustentado a partir dela, tornando aceitável a figura do homem como riqueza.

O importante é salientar que estudos iniciados num período conhecido influenciaram o modo de administrar as empresas e o modo de vida da sociedade. A partir de então, "cada pessoa deve - porque é economicamente conveniente, mas também porque é 'moralmente bom' - aumentar suas habilidades, competências e destrezas a partir de 'investimentos' constantes" ${ }^{4}$.

As vantagens de tais valores para o capitalismo vão desde o aumento da motivação e dedicação de cada um, que não vendem mais sua força de trabalho, mas vendem-se a si mesmos, ao mascaramento de antagonismos de classe, pois todos são capitalistas já que "no lugar daquele que depende do salário, deve estar o empresário da força de trabalho... 'A pessoa é uma empresa'. No lugar da exploração entram a auto-exploração e a autocomercialização do 'Eu S/A" 5.

\section{Gestão empresarial - Toyotismo e ferramentas da qualidade}

Pensado inicialmente por Ohno como um sistema para aumentar a produtividade reduzindo estoques e efetivos e flexibilizando a produção ${ }^{6}, 0$ toyotismo foi muito além. Reduzindo postos de trabalho não deixou de responder às pressões de trabalhadores que já ocorriam em 1968 e 69 com a crise nos modelos taylorista e fordista e a quebra do acordo tácito entre capital e trabalho.

A redução de pessoal permitida pela autonomação, ou reorganização do lay out da fábrica, pôde ser intensificada com o avanço tecnológico e os projetos de automação. A flexibilização da produção, com intuito de possibilitar variações maiores aos produtos, foi além, possibilitando dispersar a produção em diferentes plantas de diferentes localidades. Tal flexibilização não seria possível sem os avanços tecnológicos na área de informática, comunicação, transportes, etc. Além destes, muito significativas para a atual flexibilidade são as normas e ferramentas de gestão da qualidade e produção, pois permitem o controle efetivo de empresas subcontratadas, facilitam o fluxo informacional, possibilitam liberdade para troca de pessoal e agem no

\footnotetext{
${ }^{3}$ Marx, Karl. Manuscritos econômico - filosóficos. São Paulo: ed. Martin Claret, 2004.p. 153

${ }^{4}$ Lopez-Ruiz, op. cit. pg. 38 (grifos no original)

5 Gorz, André, O imaterial: conhecimento, valor e capital. São Paulo: ed. Anablume, 2005. p. 10

- Coriat, Benjamin. Pensar pelo avesso: o modelo japonês de trabalho e organização. Rio de Janeiro: Revan - UFRJ, 1994
} 
aculturamento dos colaboradores, associando coerção, pela eficiente vigilância (ainda que mascarada) e desestabilidade do emprego, com cooptação, pelas fantasias de maior participação e desenvolvimento pessoal no trabalho.

A norma ISO 9000 tem o objetivo declarado de padronizar toda e qualquer atividade que interfira no processo produtivo, com o objetivo de minimizar falhas na qualidade, sejam elas defeitos no produto ou atrasos na entrega. Porém, um conjunto de efeitos colaterais é verificável. A padronização das atividades e seu registro em procedimentos facilitam a troca de efetivos ou, até mesmo, a terceirização de setores inteiros por empresas que só podem ser atraentes na medida em que pagam menos do que a contratante pagava a seus funcionários. Um produto pode ser terceirizado a uma empresa menor, com mão de obra mais barata por não ter os benefícios de uma transnacional e até pela sua localização, bastando fornecer à empresa contratada os procedimentos de fabricação e métodos de análise, bem como acompanhar os indicadores de processo que, obrigatoriamente, são fornecidos através de laudos e relatórios da contratada.

Elementos da norma específicos para controle de registros e dados, com o intuito de evidenciar a eficácia do sistema para os auditores e permitir a administração científica da empresa como um todo, têm a capacidade de compreender a sistemática de funcionamento de cada setor, aprendendo os saberes ${ }^{7}$ de seus funcionários. Uma grande transnacional do ramo de higiene terceirizou todo seu laboratório - o que não é pouco para uma indústria química - em 1999, não sem antes implantar a ISO 9000 e ter todas as análises registradas em métodos analíticos e as rotinas do laboratório em procedimentos. $O$ cálculo dos custos para tal processo e a escolha da empresa a contratar não seriam possiveis sem o estudo dos números fornecidos pelo laboratório como quantidade de análises, gasto de reagentes, tempo de resposta, etc. A empresa pôde trocar os "práticos" com mais de 30 anos de casa (alguns não tinham nem o segundo grau) por jovens técnicos recém formados e estagiários ganhando muito menos e sob responsabilidade de outra empresa. Um dos novos rapazes contratados, que ficou responsável pela microbiologia disse: "Eu caí de pára-quedas aqui, não tive nenhum treinamento. Todas as análises tinham um método e a rotina do setor estava descrita em procedimento, eu só precisei seguir".

Outro pilar fundamental para o sistema de gestão é o constante treinamento dos colaboradores. Tal prática normalmente é apresentada, e compreendida, como uma forma de ganho para o trabalhador que irá se aperfeiçoar,

\footnotetext{
${ }^{7}$ Estamos utilizando "saber" num sentido que será diferente de "conhecimento" (já profissionalizado). Como Gorz (op. cit.) o faz à pg. 32
} 
mas tem evidente importância na disseminação das ferramentas e, através de treinamento sobre determinada atividade produtiva são possiveis sua fragmentação e divisão entre os flexiveis trabalhadores, acostumados, agora, a exercer várias funções. O funcionário de uma consultoria contou que montara um treinamento sobre determinado processo para uma transnacional, para isso entrevistou e acompanhou o trabalho do único funcionário que conhecia a atividade durante um mês. Deu o treinamento com a ajuda dele para 20 outros funcionários. Após algum tempo ficou sabendo que a empresa o havia demitido. Tão logo outros conseguiram realizar a tarefa, ela foi dividida e sua função eliminada, embora o próprio consultor houvesse dito, para motivá-lo, a além de realizar todos os dias sua tarefa, ajudá-lo a montar o treinamento, que ele precisava ensinar o que sabia ou nunca poderia ser promovido.

Outro princípio amplamente festejado é o de melhoria contínua ${ }^{8}$, pois, dizem os consultores, se a humanidade não tivesse esse desejo de melhorar estaríamos na idade da pedra. A versão de 1994 da ISSO 9001 não possuía essa indicação de melhoria e, novamente na fala dos consultores, uma empresa podia fazer um produto de qualidade muito ruim e atender à norma, pois é a própria empresa que determina seus parâmetros da qualidade. Agora os auditores podem cobrar as melhorias ao longo do tempo, ela é obrigatória. Acontece que o conceito de melhoria contínua deve ser aplicado a tudo, portanto a produtividade deve ser cada vez maior, aumentando a eficiência da produção ao mesmo tempo em que reduz custos. Cada processo da empresa deve melhorar seus indicadores. Todos os anos os contratos com os "terceiros" devem ser renovados reduzindo o custo, trocando a empresa contratada se necessário. A velocidade das máquinas deve ser cada vez maior no setor produtivo para reduzir o tempo e assim sucessivamente. $\mathrm{O}$ aumento da régua que mede o processo como um todo nunca tem fim. E isso não significa melhor qualidade aos produtos dada a "falácia da "qualidade total' sob a vigência da taxa de utilização decrescente do valor de uso das mercadorias" $"$ - o capital tem de reduzir o ciclo de vida útil dos produtos.

Como suporte para sistemas de gestão como a ISO 9000 utilizam-se variadas ferramentas de gestão como $5 \mathrm{~S}$ (organização), Braimstorm, Ishikawa e 5W $1 \mathrm{H}$ (solução de problemas com participação de todos), entre outras. Em geral têm o objetivo declarado de facilitar o trabalho em equipe, organizando

\footnotetext{
${ }^{8}$ Na NBR ISO 9001 versão 2000 (ABNT) declarado na política da empresa (elemento 5.3) e especificado no elemento 8

9 ANTUNES, Ricardo. Os sentidos do trabalho: ensaio sobre a afirmação e a negação do trabalho. São Paulo: ed. Boitempo, 2003. p. 50
} 
os espaços de maneira racional, propiciar um ambiente mais saudável, visto que todos podem dar suas sugestões para solução de um problema e são reconhecidos por isso.

Por outro lado criam sistemas onde o trabalho passa a ser racionalizado no seu mais intimo detalhe (gavetas pessoais são organizadas para reduzir o tempo de procura por um objeto). Tais ferramentas disfarçam as reais situações de subordinação, visto que, aparentemente todos estão juntos para solucionar um problema e todas as opiniões são importantes, mas além das decisões continuarem restritas dentro da organização, esse processo nada mais faz que aproveitar as boas idéias dos trabalhadores que realmente executam as tarefas. Essas idéias economizam recursos ou tornam o trabalho mais eficiente, mas, evidentemente, os ganhos para os trabalhadores nunca são equivalentes aos da empresa. Apesar dos brindes e gratificações pelo cumprimento de metas, as quais são cada vez mais ousadas, muito mais intenso é o reconhecimento que recebem os derrotados: o setor que recebeu menor pontuação na auditoria, o dono da gaveta que foi fotografada desarrumada, o grupo que deu menos idéias.

Além dos efeitos colaterais já comentados, é preciso registrar a intensificação de trabalho que tais métodos proporcionam. Fora àquela buscada claramente (como através do CEP - controle estatístico de processos, ou Set up) que aumenta a velocidade da máquina, redistribui tarefas, etc., o trabalho cresce na medida em que é necessário atender tais ferramentas. São relatórios a serem preenchidos, documentos a serem estudados, auditorias, apresentações, um tempo tomado por treinamentos e palestras de consultores (como a experiência que tentamos simular no início do texto). Outro fator importante é que, entrando na questão do sentido do trabalho, o gasto de energia proporcionado pelo atendimento a tais sistemas é ainda mais estafante, pois se trata de uma atividade efêmera por natureza. Dada a economia de serviços que se criou, essas ferramentas precisam ser constantemente renovadas para sobrevivência de seus criadores, consultores, editores de livros, etc. Novas "modas" surgem constantemente dentro do meio corporativo e um exército de trabalhadores é obrigado a se reciclar. $O$ diretor de uma empresa nacional contou pensar que, certificado em ISO, aumentaria suas vendas, mas não foi assim. Em compensação, se não o fizesse, iria perder seus clientes. "Você não luta mais para crescer, luta para não cair".

Vale frisar que os trabalhadores intermediários entre a direção e os produtivos não estão em melhor situação que os últimos, acabam por dedicar muitas vezes dez ou mais horas do dia organizando tais sistemas, fora o tempo extra que têm de gastar se preparando para serem coordenadores de sistemas que têm validade até o próximo consultor chegar. Os trabalhadores 
desse nível intermediário da hierarquia não são executivos como, às vezes, pode se confundir. Os executivos, normalmente, fazem parte de um núcleo duro da empresa, que recebe benefícios e é estimulado financeiramente e com status. Estes que estamos comentando são engenheiros, técnicos, que coordenam equipes e gerenciam processos (como gerente da qualidade, coordenador de segurança, etc.), eles aspiram chegar a melhores posições e agarram-se aos projetos de implantação e manutenção de tais ferramentas como oportunidade de ascensão ou simples manutenção do emprego.

Além disso, o gerenciamento de tais ferramentas vem preencher o tempo, pois suas atividades vão se tornando supérfluas cada vez mais rapidamente. Outra característica da racionalidade imposta à produção é a rápida identificação de problemas e sua eventual correção ao longo do processo - os culpados são rapidamente encontrados (acabou a sabotagem). Além disso, todas as funções de supervisão vão perdendo importância diante de trabalhadores que competem entre si, um sendo o déspota do outro, trabalhadores que interiorizaram a norma. "Estamos entrando nas sociedades de controle, que funcionam não mais por confinamento, mas por controle contínuo e comunicação instantânea" 10 .

Assim como os trabalhadores diretamente ligados à produção vão tendo sua função desqualificada e, conseqüentemente, sua condição precarizada, as funções desse corpo administrativo também vão perdendo importância e suas atividades realizáveis em menor tempo conforme avançam as tecnologias e caem as necessidades de supervisão. Evidentemente, assim que isso é percebido a empresa pode realizar as reengenharias e eliminar postos distribuindo tarefas. Por isso esses trabalhadores mais qualificados têm nesses sistemas burocráticos não só a oportunidade de aparecer para a empresa como, por vezes, a chance de continuar nela, dificilmente subindo de posto (exemplo disso os próprios programas de trainee, que buscam jovens para as carreiras mais elevadas e os funcionários da casa nem podem participar).

Este é um esboço da atual administração, onde cada vez mais trabalhadores são dispensados, os que permanecem têm sua carga intensificada em quantidade e, muitas vezes, no atendimento a uma burocracia desgastante e sem significado. Se, em 1974, Harry Braverman escrevia sobre a degradação do trabalho no século XX em Trabalho e Capital Monopolista, apontando a crescente subdivisão do trabalho em tarefas mínimas e o desconforto causado por uma "alienação" cada vez maior do trabalhador frente a tarefas que nada exigiam do cérebro e uma burocratização crescente, o que dizer do sistema atual?

${ }^{10}$ Deleuze, Gilles. Conversaçóes. São Paulo: editora 34, 1992. p. 216 
Um sistema que consegue aprender os saberes do trabalhador, através de seu próprio esforço, transformar em capital de conhecimento para a empresa, que pode usar contra ele mesmo, automatizando, fragmentando ou terceirizando a atividade. Um sistema que permite transportar a tarefa para outra fábrica, cidade ou país, reduzindo a possibilidade de reivindicações. Além disso, intensifica o trabalho dos que estão na ativa por absorverem as funções dos que saíram, pelo aumento contínuo das exigências e por incorporarem atividades que os mantém num estado de alerta até mesmo fora da fábrica. Não bastasse tudo isso, tais práticas ainda têm o poder de confundir os menos atentos, fazendo-os pensar que o trabalhador recuperou muitos saberes ou ganhou conhecimento por, com uma máquina mais moderna, realizar sozinho o trabalho de um setor que antes empregava vários quando, na verdade, ele apenas aprendeu a operar a máquina, não sabe o que os outros faziam e esqueceu a sua parte. Richard Sennett, em A Corrosão do Caráter, demonstra através da padaria que estudou quando a fabricação era manual e depois de automatizada, que a nova geração de padeiros apenas apertava botões, não mais sabia fazer pão e, embora o trabalho exigisse menos fisicamente, a redução dos salários para tais funções, não mais especializadas, obrigavam-nos a terem mais de um emprego. A terceira revolução industrial não mudou o que Marx já apontara sobre a intensificação do trabalho no capítulo sobre a maquinaria e grande indústria em O Capital. "O meio de trabalho mata o trabalhador" $"$.

Relações de poder são escondidas através de reuniões que simulam igualar as condições, mas apenas são ferramentas para se apropriar dos saberes dos trabalhadores. Há uma "concentração de poder sem centralização de poder" ${ }^{12}$. "O novo capitalismo é um sistema de poder muitas vezes ilegível"13. A flexibilidade criou novas estruturas de controle. "Os trabalhadores, assim, trocam uma forma de submissão ao poder - cara a cara - por outra, eletrônica... Trabalhar em casa é a ilha última do novo regime... Na revolta contra a rotina, a aparência de nova liberdade é enganosa" ${ }^{14}$. Sistemáticas inúteis são apresentadas como soluções inteligentes, mas apenas beneficiam consultores. E, quanto a esse estado de falsas aparências vale lembrar que "a alienação não se revela apenas no fato de que os meus meios de vida pertencem a outro, de que meus desejos são a posse intangível de outro, mas de que

\footnotetext{
${ }^{11}$ Marx, Karl. O capital: crítica da economia politica. São Paulo: ed. Nova Cultural, 1988. p. 47

12 Sennett, Richard. A corrosão do caráter: conseqüencias pessoais do trabalho no novo capitalismo. Rio de Janeiro: ed. Record, 2001. p. 63

${ }^{13}$ Sennett, Richard. op. cit. p. 10

14 idem. p. 68 e 69
} 
tudo é algo diferente de si mesmo, de que a minha atividade é qualquer outra coisa...". ${ }^{15}$

"Opondo-se ao contra-poder que emergia das lutas sociais, o capital iniciou um processo de reorganização das suas formas de dominação societal, não só procurando reorganizar em termos capitalistas o processo produtivo, mas procurando gestar um projeto de recuperação da hegemonia nas mais diversas esferas da sociabilidade. Fez isso, por exemplo, no plano ideológico, por meio do culto de um subjetivismo e de um ideário fragmentador que faz apologia ao individualismo exacerbado contra as formas de solidariedade e de atuação coletiva e social" ${ }^{16}$. Dessa forma o capital intensificou sua exploração, depreciou o trabalhador e ainda se protegeu das possibilidades de organizaçã̃o e resistência.

O avanço do capitalismo e as atuais estratégias de gestão reduzem efetivos e salários, intensificam o trabalho dos que estão na ativa e desarticulam a classe trabalhadora que enxerga operadores, coordenadores, terceiros, estagiários, informais, etc., e não a "classe-que-vive-do-trabalho" ${ }^{17}$ e ainda conseguem camuflar seus reais efeitos. "Nada era escondido do trabalhador na fábrica de alfinetes [referindo-se a Adam Smith]; muita coisa é escondida dos trabalhadores da padaria. O trabalho deles é muito claro e, no entanto, muito obscuro" ${ }^{18}$.

\section{Neoliberalismo e a interação das idéias apresentadas}

Evidentemente, a busca por tais resultados não é novidade nas práticas capitalistas, muitos elementos representam intensificação de situações já observadas há muitas décadas. Importante destacar a abrangência desse ideário que ultrapassa os limites da fábrica. A articulação entre a teoria do capital humano e os resultados das novas configurações toyotistas levaram a uma situação onde o indivíduo luta para estar no mercado de trabalho e acreditase o único responsável pela sua empregabilidade. No mesmo movimento temos o avanço do neoliberalismo onde, em última instância, o Estado passa a governar para o mercado. A legitimidade das ações é substituída pela eficácia. O mercado passa a ser o "lugar de veridição" ${ }^{19}$.

\footnotetext{
${ }^{15}$ Marx, Karl. Manuscritos econômico - filosóficos. São Paulo: ed. Martin Claret, 2004. p. 157 (grifos no original)

${ }^{16}$ Antunes, Ricardo, op. cit. p. 48 (grifo no original)

${ }^{17}$ idem. pg. 101

${ }^{18}$ Sennett, Richard. op. cit. p. 88

${ }^{19}$ Foucault, Michel. Naissance de la biopolitique. Coll. Hautes Études. Paris: Galimard/Seuil, 2004. p. 33
} 
Se por um lado o enxugamento do Estado agrava a necessidade de conseguir se vender, diminuindo qualquer apoio em saúde, educação e aposentadoria de qualidade, por outro, as idéias neoliberais fazem coro com as exigências toyotistas e o ideário do capital humano, resultando na crença do indivíduo capitalista de si mesmo, único responsável por sua colocação no mercado, bem sucedido na vida somente quando bem sucedido nele, em permanente competição com os outros e que deve constantemente investir em sua formação, empregabilidade e em seu capital. "A introjeção do cálculo econômico no mais íntimo da vida tem por corolário a máxima exposição do sujeito a um poder que o manipula" ${ }^{20}$.

A inesgotável busca por mais valor abstrato, a supervalorização do novo e a competição crescente pelas vagas de um mercado que diz só ter lugar para os melhores, resulta na eterna procura por aprendizado e superação de si, "nas sociedades de controle nunca se termina nada" ${ }^{21}$.

Apesar do desemprego e do desgaste gerado pela constante necessidade de atualização e reciclagem, a esmagadora maioria adere à lógica prescrita pelo capital humano, exigida pelas práticas toyotistas e tornada incontestável pelo regime de verdade do mercado. "A esperança obstinada de se impor contra as outras pessoas (vistas como concorrentes), mediante disposição ao trabalho, conhecimento e empurrões, não apenas é animicamente perversa (...), mas também completamente ilusória do ponto de vista socioeconômico, porque o sistema produtor de mercadorias, em seu atual nível de desenvolvimento, tem de produzir perdedores em massa" 22.

Sennett aponta como, em A riqueza das naçôes, Smith indicou o conceito "demasiado alienante" de que a maioria dos homens supervalorizava suas chances de ganho. Cita, também, uma pesquisa com um milhão de estudantes secundaristas na qual $70 \%$ julgavam ter capacidade de liderança acima da média, e somente $2 \%$ abaixo ${ }^{23}$.

Dessa forma temos uma sociedade que aplaude programas de $\mathrm{T} v$, reality shows, onde se compete por emprego, como O Aprendiz da People and Arts e Record, ou garotos de 15 anos sofrem para um se tornar jogador de futebol, como o Joga $10 \mathrm{da} \mathrm{Tv}$ Bandeirantes. "Se os jogos de televisão mais idiotas têm tanto sucesso é porque exprimem adequadamente a situação de empresa" ${ }^{24}$. Não se têm mais amigos, mas network, não se goza férias, mas investe-se

\footnotetext{
${ }^{20}$ Santos, Laymert G. Texto inédito. Comunicado pelo autor, 2005

${ }^{21}$ Deleuze, Gilles. op. cit. p. 221

${ }^{22}$ Kurz, Robert. O colapso da modernização. São Paulo: ed. Paz e Terra, 1999. pg. 138 (grifos no original)

${ }^{23}$ Sennett, Richard. op.cit. p. 106

${ }^{24}$ Deleuze, Gilles. op. cit. p. 221
} 
em qualidade de vida. Tudo é movido pelo cálculo e interesse. Não pode ser apenas força de expressão - e comentamos as teorias do capital humano escolas fazerem sua propaganda aconselhando os pais a investirem na educação dos filhos, pois eles são a melhor aposentadoria. "A vida está se transformando cada vez mais em commodity, e as comunicações, a comunhão e o comércio estão se tornando indistinguíveis". ${ }^{25}$

\section{Alguns sintomas contemporâneos}

"O movimento do capitalismo é produção de mercadoria; e, como produção de mercadoria, é produção de artifício, de fetiche; nesse sentido, quanto mais produz artifício, mais o capitalismo inscreve a abstração na realidade, quer dizer na sociedade. A tendência do capitalismo é (...) dissolver o sentido que se atribuía anteriormente às pessoas, às coisas, aos valores para colocar em seu lugar $o$ valor, quantidades abstratas de riqueza e trabalho..." ${ }^{26}$. "É precisamente o seu caráter desterritorializante, descodificante que o faz esquizofrenizante". ${ }^{27}$

No Japão, dezenas de familias perdem parentes por karoshi, morte por excesso de trabalho. Os ingleses batem recordes de afastamento por motivos ligados ao estresse e gastam bilhões com terapia ${ }^{28}$. Segundo a Organização Mundial da Saúde, 30\% dos trabalhadores no mundo apresentam sintomas de depressão, transtornos de ansiedade (como síndrome do pânico) ou estresse. A OMS estima que transtornos depressivos saltarão do quarto lugar que ocupam hoje, no ranking de doenças mais onerosas, para o segundo até $2020^{29}$.

É interessante observar as opiniões de psicólogos que começam a apontar a insatisfação dos trabalhadores ligada à falta de sentido e os resultados disso para a saúde mental. "Odair Furtado, professor de Psicologia Social da PUC de São Paulo, acredita que a insatisfação e a falta de sentido têm origem nos fundamentos do capitalismo, na venda da força de trabalho que se transforma em mercadoria" ${ }^{30}$. Estelle Morin, Ph.D. em Psicologia Organizacional

\footnotetext{
${ }^{25}$ Rifkin, Jeremy. A era do acesso. São Paulo: Makron Books, 2001. p. 8

26 Santos, Laymert G. Alienação e Capitalismo. São Paulo: ed. Brasiliense, 1982. p. 88 (grifo no original)

27 Idem. p. 92

${ }^{28}$ Criteos - Centre de recherche et d'intervention pour lê travail, l'efficacité organisationnelle et la santé (pg. oficial na internet - http://web.hec.ca/criteos/index.cfm)

${ }^{29}$ World Health Organization (pg. oficial na internet - www.who.int/en)

30 Revista Carta Capital. São Paulo: Ed. Confiança, Ano X, no 263 de 22/10/2003. p. 15
} 
e Industrial, comenta que verificou na pesquisa de campo que realiza desde 1995 a importância do trabalho ser considerado ético e fazer sentido, sendo que, quando considerado inútil, a tendência é de que as pessoas considerem suas vidas como inúteis. "Nos últimos três ou quatro anos houve um aumento significativo de faltas justificadas no trabalho por doenças mentais. Muitos estão entrando em colapso. Dedicaram-se tanto para manter seus empregos e deram tanto pelas organizações que acabaram sem forças" ${ }^{31}$.

Conforme avançam a racionalidade técnica e a tecnologia, fica cada vez mais evidente o desgaste nas tentativas de superação para atender a um sistema que muda de forma acelerada. Desabafos na forma de livros como Bonjour Paresse (2004), da suiça Corinne Maier, e Chega de Oba-Oba! (edição brasileira de 2005) da alemã Judith Mair, denunciam o cinismo das empresas em defender a felicidade no trabalho, as ferramentas de gestão como formas de medir as pessoas, as exigências de dedicação e como o horário flexivel colocou trabalho no que ainda era particular. O progresso e o estilo de vida materialista também são questionados em livros como The Progress Paradox: How Life Gets Better While People Fell Worse de Gregg Easterbrook.

Por outro lado, a eficiência da produção de desejo no atual sistema produtor de mercadorias - "o marketing é agora o instrumento de controle social" ${ }^{32}$-, a confiança de ser um dos vitoriosos mesmo que sejam poucas as vagas e a crença na falta de alternativa proclamada pelo mercado, resulta numa corrida cega para se reciclar, superar e valorizar. Relatos do meio empresarial e dos reais efeitos das práticas atuais são apresentados por revistas e profissionais empenhados em defender essa lógica. Ou seja, ao invés de causarem um questionamento dessas práticas, reforçam o conceito de que o profissional tem de capacitar-se, até mesmo emocionalmente, para de adaptar às mudanças. Embelezam a vitória no jogo. Os "desabafos na forma de livros" citados acima, tiveram sua apresentação ao público brasileiro pela revista VOCÊ S.A. ${ }^{33}$, líder no segmento de publicação sobre carreiras. Uma entrevista com Richard Sennett, comentando os estudos presentes em seu livro que é citado ao longo desse texto, foi considerada como uma das melhores entrevistas na edição de aniversário da revista ${ }^{34}$. É como se todos os avisos do poder nefasto da dinâmica atual servissem para valorizar ainda mais os que conseguem o "sucesso" e intensificar o esforço dos que o buscam.

\footnotetext{
${ }^{31}$ Idem. p. 16 e 17 (grifo nosso)

${ }^{32}$ Deleuze, Gilles. op. cit. p. 224

${ }^{33}$ Revista você s.a. São Paulo: ed Abril. No 87, setembro de 2005. p. 42 a 45

${ }^{34}$ Revista você s.a. São Paulo: ed Abril. No 86, agosto de 2005. p. 46 e 47
} 


\section{Considerações finais}

As mutações das últimas décadas têm um alcance que vai além dos limites da fábrica, havendo ocorrido mudanças no plano econômico, político e ideológico. Dessa articulação surgem novas situações e desafios: 1) precarização em escala global possibilitada pelas novas tecnologias e técnicas de gestão, 2) um ideário de que não há alternativa, uma subsunção de tudo ao mercado, crença na valorização do capital humano e na competição, 3) sistemas de gestão eficientes em aprender as capacidades cognitivas dos trabalhadores enquanto se escondem em um discurso "humanizador" 35 complementado pelo discurso do emprendedorismo, 4) a assimilação desses discursos não somente pelos cargos mais altos da hierarquia empresarial, mas também pelo restante da cadeia e pela sociedade em geral (prefeituras também vêm implantando sistemas de gestão baseados nesses modelos, qualquer cidadão comum vive preocupadíssimo com a saúde do mercado financeiro, etc.), 5) cada vez menos possuem trabalho e estes trabalham muito mais, além do desgaste na eterna insegurança, na constante busca por qualificação e na competição.

Estes são apenas alguns pontos que estão de tal forma interligados que fica difícil mesmo sua descrição como elementos distintos. E seus resultados não encontram paralelo na era moderna. Quem tem o "privilégio" de vender a força de trabalho está dando sinais de esgotamento.

\footnotetext{
35 Wolff, Simone. Informatização do trabalho e reificação: uma análise à luz dos programas de qualidade total. Campinas,SP: ed. da unicamp; Londrina, PR: Eduel, 2005. 11-12
} 